DOI:

\title{
Tarihi Yapıların Yeniden İşlevlendirilmesinde Çelik Strüktürlerin Kullanımı: Kasımpaşa Tuz Ambarı Örneği
}

\author{
Füsun SEÇER KARİPTAŞ1 ${ }^{*}$, Fatih KARİPTAŞ²
}

${ }^{1}$ Haliç Üniversitesi, Mimarlık Fakültesi, İç Mimarlık Bölümü, İstanbul, Türkiye ORCID ID: orcid.org/0000-0003-1594-6061

2 MSGSÜ, Mimarlık Fakültesi, İç Mimarlık Bölümü, İstanbul, Türkiye ORCID ID: orcid.org/0000-0001-7930-1508

*Sorumlu Yazar e mail: fusunsecer@halic.edu.tr

Geliş Tarihi: 26.01 .2020

Kabul Tarihi: 10.02 .2020

Atıf/Citation: Seçer Kariptaş, F. ve Kariptaş, F. “Tarihi Yapıların Yeniden İşlevlendirilmesinde Çelik Strüktürlerin Kullanımı: Kasımpaşa Tuz Ambarı Örneği”, Haliç Üniversitesi Fen Bilimleri Dergisi 2020, 3/1: $73-84$.

Araştırma Makalesi/ Research Article

\section{Özet}

Endüstrileşme olgusu içinde ortaya çıkan ve son zamanlarda endüstri mirası olarak kabul edilen ve tarihinin önemli tanıkları sayılan endüstri yapıları gelişen teknolojiye de bağlı olarak kent dokusu içerisinde terk edilmeye başlanmıştır. Günümüz kentleri içerisinde fonksiyonunu ve önemini yitirmiş olan endüstri yapılarının yıkılmaları veya metruk hale gelmeleri yerine, çağdaş koruma yaklaşımı ile insanlığa ve topluma hizmet veren mekânlar olması hedeflenmektedir. Endüstri mirası bu yapıların yıkılmadan yeni kullanımlara sunulması, sıfırdan inşa etmeye oranla daha ekonomik olsa da tasarımında ve uygulanmasında titiz bir çalışma yapılması gerekmektedir. Yapıların tarihi değerlerine mümkün olduğunca az zarar verecek çözümler üretilmeye çalışılmalıdır. Çelik strüktürler bu çözümlerden biridir. Şeffaflık, hafiflik, serbest formlar oluşturması, büyük açıklıklar geçebilmesi ve esneklik özellikleri nedeniyle çeliğin kullanımı ile birçok yeniden işlevlendirme uygulamasında karşılaşılabilmektedir. Kasımpaşa Tuz Ambarı endüstri mirası kapsamında bir yapı olduğundan restore edilerek yeniden işlevlendirilmiştir. Reklam ajansı olarak yeniden tasarlanan yapının iç mekânında çelik strüktürler kullanılarak restorasyon çalışması tamamlanmıştır. Bu çalışmada, tarihi binaya zarar vermeden ve çelik taşıyıcılarla yeniden tasarlanan, bu özelliği ile mimari alanda ülkemize ödül de getiren bu uygulamanın ileride yapılacak çalışmalara örnek olacağı düşünülmektedir.

Anahtar Kelimeler: Endüstri mirası, Yeniden işlevlendirme, Çelik, Strüktür, Tuz ambar1. 


\title{
Re-functioning Historical Buildings Using Steel Structures: Example of Kasımpaşa Salt Repository
}

\begin{abstract}
Industrial structures which are considered as important witnesses of industrial history, produced within the concept of industrialization and accepted as industrial heritage, begin to disappear within the urban texture due to the developing technologies. Rather than getting demolished or abandoning the industrial buildings which have lost their function and significance, the current urban texture should be able to include these spaces through contemporary preservation approaches that serve people and societies. Although re-functioning these industrial heritage buildings is more economical compared to building compelety new structures, the design and application require a thorough study. The architectural solutions should not interfere with the historical value of the buildings as much as it is possible. Steel structures are one of the solutions. It is possible to encounter steel structures in re-functioning applications due to the material properties of transparency, lightness, ability to produce free forms, spanning long distances and flexibility. Kasımpaşa Salt Repository which is an example of industrial heritage has been re-functioned. The interior of the building which has been re-designed as an advertising agency has been completed by using steel structures in its restoration. In this study, the appliance of steel structures in re-designing historical structures with no harm done to it, which has brought forth a reward for our country, has been put forward as an exemplary implementation for future studies.
\end{abstract}

Keywords: Industrial heritage, Refunctioning, Steel, Structure, Salt repository.

\section{Giriş}

Endüstri, ekonomik bir kavram olarak ham madde ve ara malların mevcut bilgi, beceri ve teknolojilerden yararlanılarak ve işçi emeği kullanılarak fabrika ve üretim tesislerinde mal ve/veya hizmete dönüştürülmesi olarak tanımlanabilir. Endüstri için dört temel unsur bulunmaktadır: Doğal kaynaklar, emek, sermaye ve yönetim. Tüm bu unsurlar birbirini tamamlayıp endüstriyi oluştururlar [1]. Bir devrime neden olan endüstrileşme çabaları özellikle İngiltere'de başlayan girişimlerle giderek Avrupa'ya yayılmıştır. Makinelerin insan hayatına 
girmesinin ardından sanayi hızla makineleşmiş ve buna bağlı olarak da endüstrinin tüm alanlarında üretim artışı olmuştur. Bu hızlı makineleşme gerçeği endüstrinin tek bir koluyla sınırlı kalmayıp bütün üretim kollarını kontrolü altına almıştır. Yeni makinelerin icatları ile birlikte tarımda, dokumada ve ulaşımda kısacası endüstrinin tüm alanlarında ve buna paralel olarak da toplumda üretim adına değişimler yaşanmaya başlamıştır.

Ülkelerin zenginleşmesi ile endüstrileşme arasında kuvvetli bir bağ vardır. Bir başka deyişle ekonomik kalkınma ile endüstrileşme doğru orantılıdır. Endüstrileşme süreci toplumların ekonomik, sosyal, siyasal ve hatta kültürel yapılarında köklü değisşimler yaratan bir oluşumdur. Endüstrileşmenin doğuş tarihi 18. yüzyılın sonu ile 19. yüzyılın başı olarak kabul edilmektedir.

Yaşadıkları dönemin endüstrisini anlatan tüm araçlar, yapılar ve peyzajlar endüstri mirası olarak kabul edilmektedir. Bu miras kapsamındaki eserler korunurken dikkatli bir çalışma yapılması gerekmektedir. Endüstri mirası kapsamındaki yapıların, günümüz şartlarına göre değerlendirilmesinde, yeniden işlevlendirmeyi gerektiren sebepler ve işlev seçimini etkileyen faktörler ele alınmalıdır. Yeniden işlevlendirilerek ayakta kalması sağlanan tarihi yapıların restorasyonu sırasında çelik strüktürlerin kullanılması son dönemlerde başvurulan bir çözüm olarak kabul edilmektedir. Böylece büyük açıklıklı ve yüksek tavanlı endüstri yapılarında ana strüktüre dokunmadan kendi içinde çözümler üretilebilmektedir. Kasımpaşa Tuz Ambarı örneği yeniden işlevlendirme süreci geçiren önemli örneklerden biridir. Tuz Ambarı'nın rölöve çalışmalarına 2008 yılı başında başlanmış, aynı yılın sonunda da restorasyonu tamamlanmıştır. Projenin tasarımı ve uygulaması Erginoğlu\&Çalışlar Tasarım Merkezi tarafından gerçekleştirilmiştir. Yapılan projede taş duvarlara dokunulmadan kendi içinde oluşturulan bir çelik strüktürle asma katlar ve yeni mekânlar yaratılmıştır. 


\section{Materyal ve Metot}

Bu çalışmada, tarihi ve özellikle endüstri mirası kapsamındaki yapıların yeniden işlevlendirilmesi sırasında çelik strüktürlerin kullanılması ile ilgili yerli ve yabancı örnekler incelenmiş, örnek yapı olarak da yerinde uygulaması yapılan Tuz Ambarı binası seçilmiştir.

\subsection{Endüstri mirası kavramı}

Endüstri devrimi sonrasında yaşanan kentsel dönüşümlerin kent kimliğini yok etmesi ile kültürel miras kavramı ortaya çıkmıştır. Zamanla kültürel mirasın sınırları genişlemiş ve "endüstriyel miras" gibi kültürel mirasın yeni bir boyutu ortaya çıkmıştır. Avrupa "endüstriyel kültür mirası" kavramının ortaya çıkışında öncülük etmiş, bu kavramın doğuşuyla birlikte endüstri yapılarının kültürel kimlik açısından taşıdığı öneme dikkat çekilmiştir. Teknolojinin gelişmesiyle her geçen gün yetersiz kalan üretim teknikleri nedeniyle, endüstri yapılarının terk edilmeleri karşısında gösterilen tepkiler bu alandaki koruma çalışmalarını tetiklemiştir.

\subsubsection{Endüstri mirası kapsamı ve sınıflandırılması}

Endüstriyel miras kavramı özellikle ülkemiz için oldukça yeni olan bir kavramdır. Birçok şey teknolojik bakımdan ilginç olduğu için muhafaza edilmiştir. Bunlar, moda olan makinelerin modelleri, farklı tekniklere ait kayıtlar ve sergiler, öğretim araçları, muhtelif eşyaya ait sergilerin kalıntıları, iş ya da ticaret münasebetiyle kuşaktan kuşağa geçen kişisel eşyalardır [2].

Endüstri mirası hem yer altındaki hem de yer üstündeki yapılarla ilgilenmektedir. Endüstriyel geçmişten anladıklarımızın değerlendirilmesi, endüstri yapılarının yeniden kullanılması, endüstri ürünlerinin müzelerde sergilenmesi, korunmuş demiryollarının işletilmesi, yapıların konservasyonu için modellerin üretilmesi, teknoloji tarihi ve ekonomi tarihi çalışmaları olarak tanımlanmaktadır [3]. 
Taşınmaz ve taşınır endüstri mirası kavramından bahsedilirken, endüstriyel alanla ilişkili olan ve endüstriyel süreç sonucunda ortaya çıkan, yapı olan ya da olmayan tüm birimler, yapılar ve sahip oldukları donanımlar, ekipmanlarıyla birlikte fabrika binaları, endüstriyel süreç sonucu ortaya çıkan tüm ürünler kültürel gelişimin birer aracı olarak, endüstriyel miras olarak algılanmaktadır. Bu bağlamda, en geniş kapsamıyla endüstri mirası kapsamında, madencilik, yel değirmenleri, su çarkları ve buhar makineleri gibi enerji kaynakları; tekstil, çömlekçilik, cam, yiyecek, içecek yapımı gibi üretim endüstrileri; yol, köprü, kanal ve demiryolu gibi ulaşım araçları; taş ocağı, tuğla atölyesi, bıçkı fabrikası gibi yapı malzemesi üreten yerler; üretim ve sosyal tarihin bir parçası olan endüstri işçileri, yöneticiler ve fabrika sahipleri için yapılan konutlar; gaz, su ve iletişim gibi kamu hizmeti için oluşturulan sistemlerin" incelendiği ve endüstri ile bağlantılı her alanın bu kapsama girdiği görülmektedir [3].

\section{Bulgular ve Tartışma}

Çalışma kapsamında endüstri mirası kavramı ve sınıflandırılması konusunun incelenmesi sonucunda, Tuz Ambarı binasının bu kapsamda değerlendirilebildiği görülmüştür. Tarihi bir değere sahip olan endüstri binasının yeniden işlevlendirilmesine karar verilmiştir. Yerinde yapılan çalışmalar sonucunda yapıya en az müdahale ile bir çözüm yolu aranmıştır. Çelik strüktürler sayesinde istenen çalışma yapılabilmiştir.

\subsection{Yapılarda çelik strüktürlerin kullanımı}

Çeliğin yapılarda kullanımı tarihte ve günümüzde oldukça tercih edilen bir durum olarak görülmektedir. Demir ve çelik yaklaşık beş yüz yıldır kullanılmakla birlikte ilk kullanımı İngiltere'de ortaya çıkmaktadır. İnşaat sektöründe demirin kullanımı ilk olarak köprülerle başlamıştır. 18.yüzyılın sonlarına doğru çelik üretimine başlanmıştır. Yine İngiltere bu dönemde çelik piyasasına hâkim olmuştur. Bu nedenle 
birçok ülke İngiltere'den mühendisler çağırarak kendi ülkelerinde fabrika kurulmasında yardım istemişlerdir. Bu dönemde endüstrinin gelişimi ve hızla günlük hayata girmesi yaşanmıştır. 1846 yılında inşa edilen 140 metre açıklıklı Britannia Köprüsü ile çelik kullanılarak dolu gövdeli ve ana kirişli köprülerin yapımına başlanmıştır. Özellikle fabrika yapılarında üretimin artması ve büyük açıklıklı, yüksek tavanlı mekânlara ihtiyaç duyulması nedeniyle çelik strüktürlerin imkânlarından yararlanılmıştır. Çelik karkas olarak yapılan ilk bina 1876 yılında İngiltere Diserington Flax Derğirmeni'dir [4].

19.yüzyılda çelik strüktür kullanımı hızla artmış, birçok yönden avantajlı olduğu anlaşılmıştır. Türkiye'de 1835 yılında kurulan Feshane binası, çıkan bir yangın sonucunda zarar görünce 1868 yılında yeniden inşa edilmiştir (Şekil 1). Tüm taşıyıcısı çelik prefabrik olarak yapılan ve kolonları Belçika'da döküm olarak inşa edilen yapı ülkemizdeki önemli örneklerdendir [5].

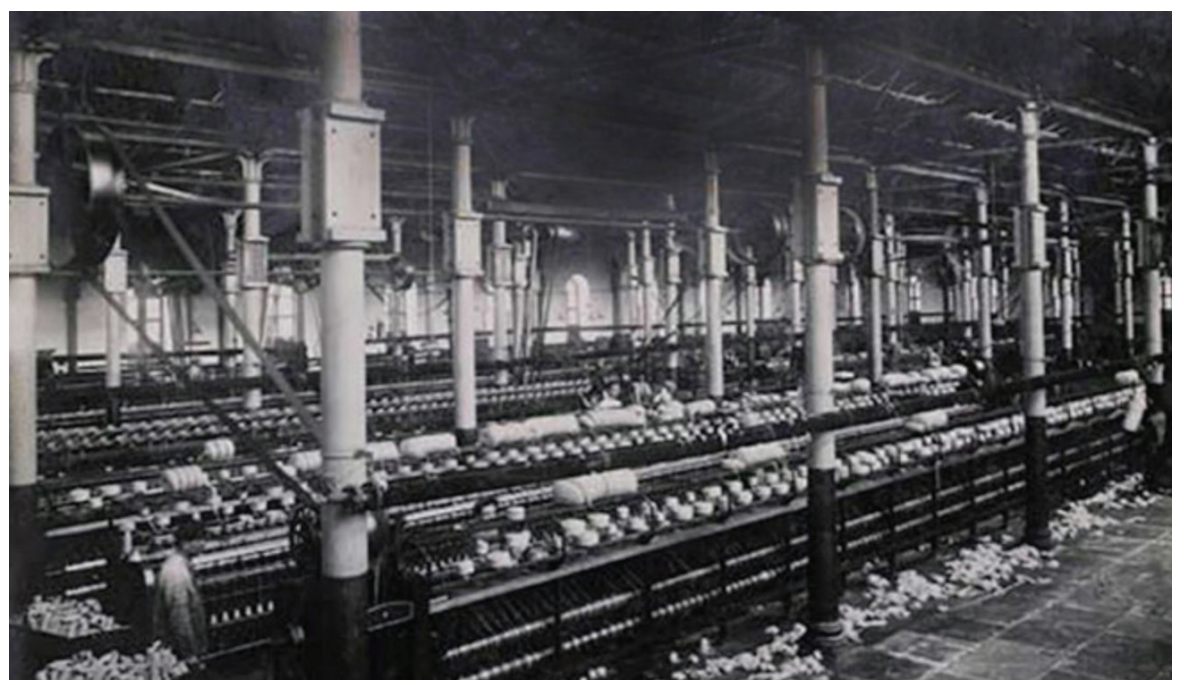

Şekil 1. Feshane binası iç mekânı ve çelik prefabrik taşıyıcı sistemi [9].

Mimaride büyük açıklıklar geçilebilmesi, şeffaf, hafif ve depreme karşı dayanıklı olması gibi özellikleri nedeniyle uzun yıllardır tercih edilen çelik gücünü hiç kaybetmemiştir. İnşaat süresini kısaltması, 
yapı ağırlığının, kolon sayısının az olması, temel maliyetin düşmesi, sökülüp takılabilir olması, değişikliklere kolayca adapte olması ve mekanik, elektrik tesisatlarının dağılımında kolaylık sağlaması da uygulama sırasında büyük kolaylık sağlamaktadır [6].

Taşıyıcı olarak çelik sistemlerin kullanımı birçok farklı şekilde olabilmektedir. Çelik bağlayıcılar yardımı ile çok katlı yapıların oluşturulması, çelik çerçeve modül sistem kullanılması, var olan farklı yapı sistemlerine hafif çelik çerçeve sistemlerle ekler yapılabilmesi, çatı sistemlerinde ve çatı katı eklemelerinde hafif olması nedeniyle kullanılması mümkündür. Ayrıca soğukta şekillendirilmiş çelik profillerden üst örtü, küpeşte, parmaklık ve yapı aksesuar tasarımı da yapılmaktadır [7].

Yapı bileşenlerinin taşıyıcı sistemle bütünleştirilerek yapı elemanlarının oluşturulmasında her geçen gün farklı teknikler denenmektedir. Teknoloji hızla gelişmekte ve inşaat sektöründe de bu gelişmelerin yansımaları görülmektedir. Ancak çelik stürktürlerin kullanılması günümüzde de birçok avantajı nedeniyle tercih edilmeye devam etmektedir. Özellikle son y1llarda restorasyon projelerinde de çelik strüktürlerin kullanımı, hem iç mekânda hem de taşıyıcı sistemde destekleyici olarak tercih edilmektedir. Kasımpaşa Tuz Ambarı Binası'nın restorasyon çalışmasında da çelik strüktür kullanılarak yapının kendi kimliğini koruyarak ayakta kalması adına bir proje yapılmıştır.

\subsection{Kasımpaşa tuz ambarı binasının restorasyonu ve çelik strüktür kullanımı}

Kasımpaşa Havuzbaşı Değirmen Sokak’ta bulunan Kasımpaşa Tuz Ambarı, asıl Kasımpaşa Değirmen binasının ambarlarından birisidir. Doğal taş kullanılarak yapılmış olan Tuz Ambarı iki binanın birleşmesinden oluşmaktadır. Tek katlı olan bu bina uzun bir süre Plytas Un Fabrikası olarak bilinen değirmenin buğday ambarı olarak kullanılmış, daha sonraki yıllarda bina tuz ambarı olarak işlevini sürdürmüştür (Şekil 2). İkinci dereceden tarihi eser olarak tescil edilmiş? yapı, 
muhtemelen tersane bölgesine hizmet vermek amacıyla inşa edilmiştir. Endüstri mirası kapsamındaki Tuz Ambarı yapısı 1980'li yıllardan beri kullanılmamış, uzun zamandır boş durması yapının bozulma sürecini hızlandırmıştır [5].

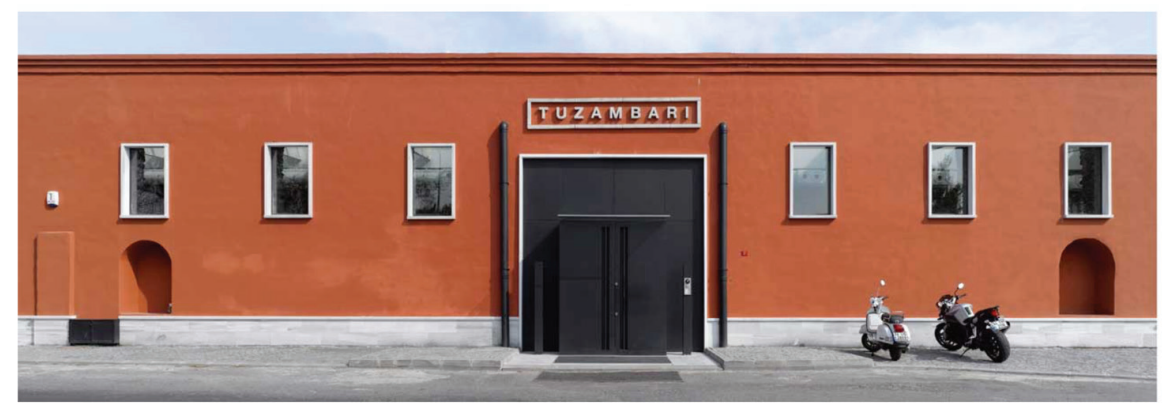

Şekil 2. Tuz Ambar1 görünümü [8].

İkinci derece tarihi eser olarak tescil edilmiş Kasımpaşa Değirmeni ve Kasımpaşa Tuz Ambarı, muhtemelen tersane bölgesine hizmet vermek amacıyla inşa edilmiş, dönemin önemli endüstri yapılarından biridir (Şekil 3). Kasımpaşa semti, şehir merkezinde olan bir bölgedir. Gerek trafiğin yoğunluğu gerekse Haliç bölgesinin endüstri yapıları için uygun bir çevre olmadığı düşünüldüğünde binanın yeni bir işlev ile değerlendirilmesine karar verilmiştir. Cepheleri özgün olarak korunan binanın içinde, yeni işlevin gereği olan bazı değişiklikler ve ekler yapılmıştır (Şekil 4). Kasımpaşa Tuz Ambarının yenileme çalışmaları sırasında binanın orijinal haline sadık kalınmıştır. Reklam ofisi adını bile değiştirmemiş ve binanın kapısına Tuz Ambarı yazarak binaya olan saygısını dile getirmiştir. Yeni bir kapı ya da pencere açı1mamıştır. Sadece çelik konstrüksiyonla asma kat eklenmiş, hatta asma katlar arasındaki geçişin sağlandığı koridorların kapıları bile ambarın orijinal pencerelerinin üzerine kurulmuştur. 


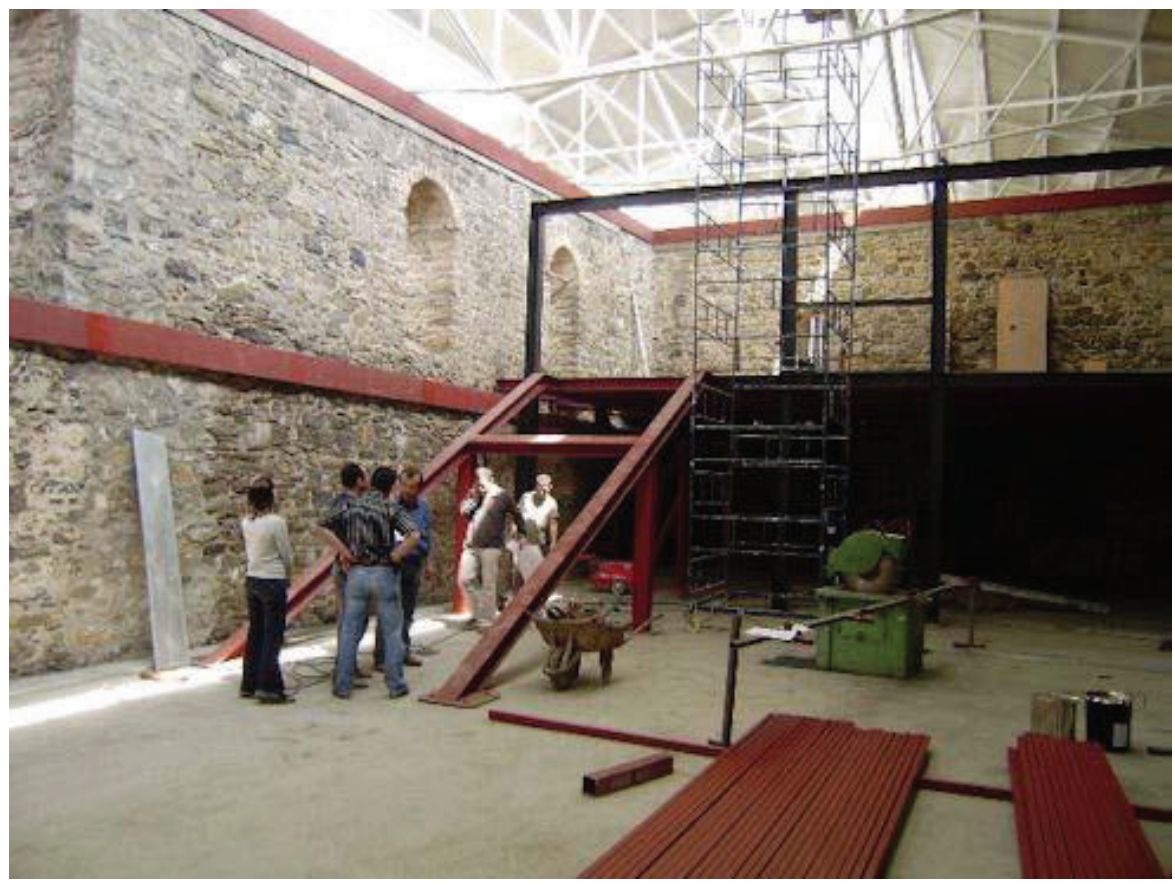

Şekil 3. Tuz Ambarı restorasyonu sırasında çelik strüktürlerin kurulumu [8].

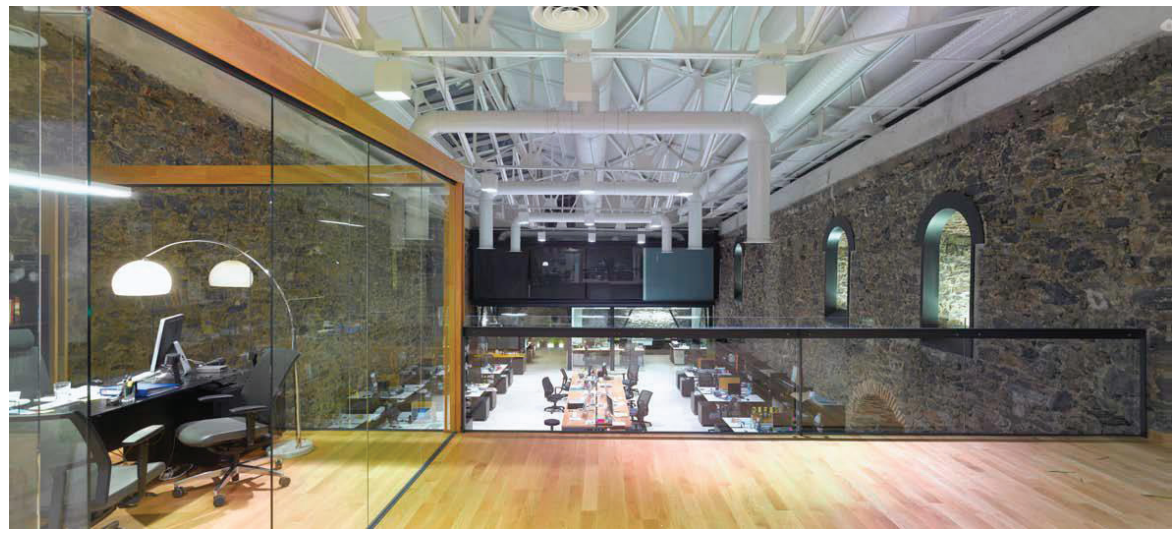

Şekil 4. Kasımpaşa Tuz Ambarı restorasyon sonrası iç mekân görünüşü [8]. 
Tuz Ambarı yapısında sekiz ayrı depo bölümü üç koridorla birbirine bağlanmıştır. Orta bölümde yer alan dört depo, iki koridorla birlikte kenarlarda bulunan depo bölümlerinden ayrılmıştır. Yapının restorasyon projesine başlamadan önce bozulma durumu incelendiğinde tümüyle yok olan bölümlerin yanı sıra, mekân, cephe, strüktür ve malzeme özellikleri açısından bozulmalar yaşadığı gözlemlenmiştir. Restorasyon projesi bu gözlemler 1şığında, yapının özgün karakteri, ölçeği, kütle ve malzemesiyle uyumlu olarak tasarlanmıştır. Yapının taş duvarları korunmuş, ikinci bir strüktür olarak çelik asma katlar tasarlanmıştır. Yeni bir kapı ya da pencere açılmamıştır. Sadece çelik konstrüksiyonla asma kata eklenmiş, hatta katlar arasındaki geçişin sağlandığı koridorların kapıları bile ambarın orijinal pencerelerine denk getirilmiştir (Şekil 5).
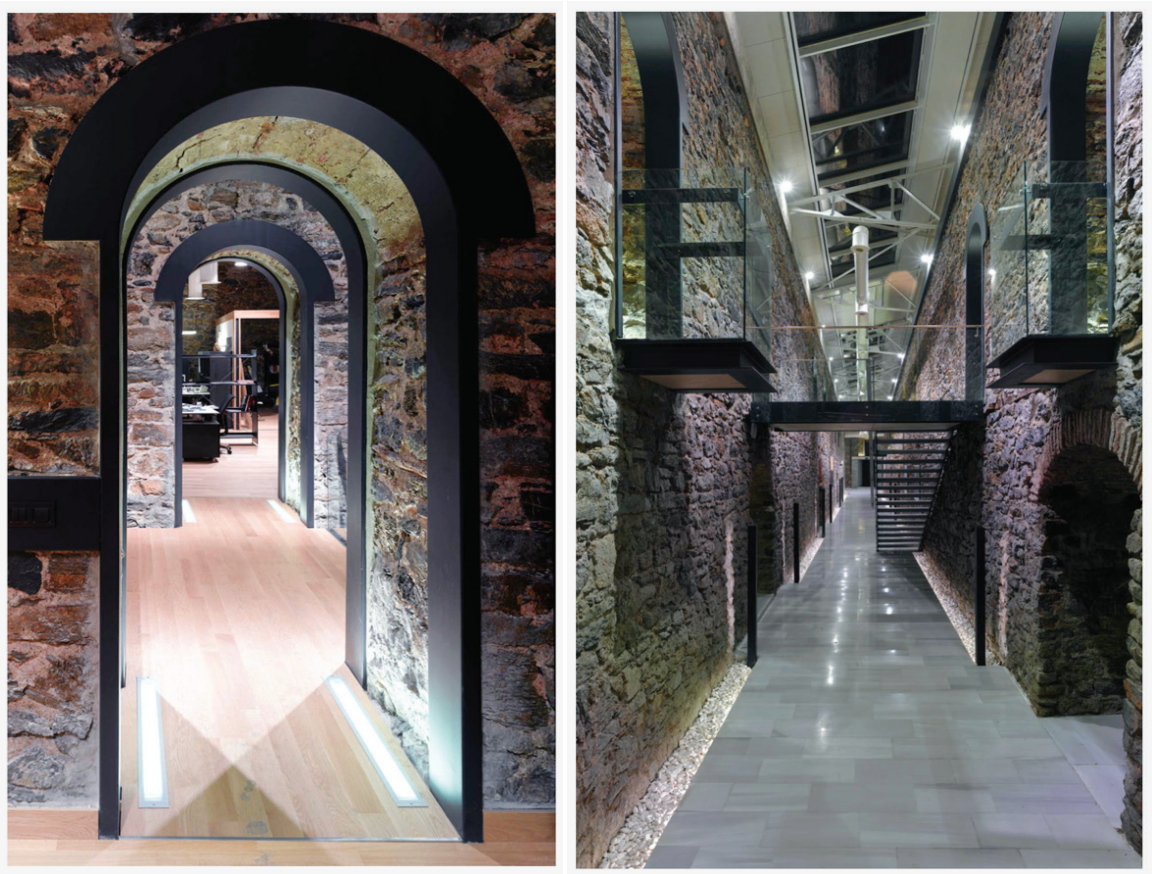

Şekil 5. Tuz Ambarı iç mekân görünümleri ve çelik kullanımı [8]. 
Tuz Ambarı restorasyon projesinde özellikle dikkat çeken dış kabuğa dokunulmadan tamamen iç mekânda tasarlanan çelik strüktürle yeniden işlevlendirmenin başarılabilmesidir. Burada kullanılan çelik strüktür sisteminde, HEA 180-HEA200 çelik kolonlar kullanılmış, ana kirişlemelerde IPE160 tercih edilmiştir. Bu kirişlere zit yönde 40x60 mm kutu profil kılıcına kullanılmıştır. Ayrıca döşemede kutu profillerin üzerine vidalanan $18 \mathrm{~mm}$ OSB ile aralarına izolasyon bandı geçilmiş, onun da üstüne ahşap lamine parke uygulanmıştır. Çelik kolonlar zemine ankre edilmeden önce bağlanacağ $40 \times 40 \mathrm{~cm}$ ebadında ve $2 \mathrm{~cm}$ kalınlığındaki plakalar betonarme temele rod, bulon, vida ve kimyasal yapıştırıcılar ile bağlanmıştır. (Şekil 6). Yatay hareketi önlemek için döşeme düzlemlerinde L70 mm korniyerler, bazı aks aralarındaki düşey düzlemlerde de kutu profillerle çaprazlar yerleștirilmiştir. Tüm strüktürel sistem sadece zeminle ilişkilendirilmiş, kesinlikle duvarla bağlantısı yapılmamış, asma katların yükleri tarihi duvarlara verilmemiştir.
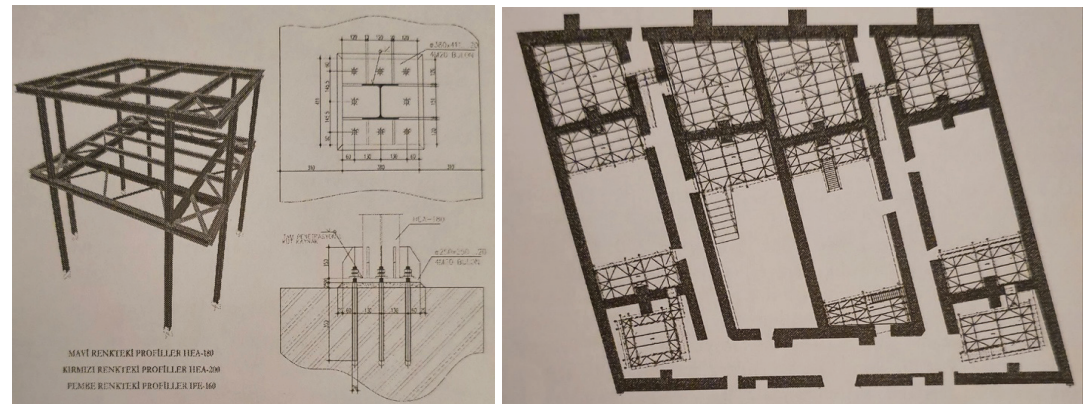

Şekil 6. Kasımpaşa Tuz Ambarı çelik sistem detayı ve planı [8].

\section{Sonuçlar}

Batılılaşma devrinde inşa edilen endüstri yapıları, o dönemin teknolojisini ve ekonomik düzenini aktarması, toplumun yaşadığı belirli bir süreci yansıtması açısından büyük bir öneme sahiptir. Endüstri yapıları diğer anıtsal bina türleri kadar önemsenmemiş dolayısıyla korunmamışlardır. 
Zamanla fonksiyonunu yitiren bu yapılar boş ve bakımsız kalarak hızla tahrip olmuşlardır. Bugün harap ve bakımsız olan ve hatta çok az bir kısmı ayakta kalan endüstri yapılarının, zaman içinde hasar görmesini önlemek ve binaların mümkün olduğunca korunmasına çalışmak gerekmektedir. Bu amaçla, bu tür yapıların acilen tespit, tescil ve belgeleme çalışmalarını içeren detaylı araştırmaları yapılmalı ve rölöveleri hazırlanmalıdır. Binalar çok iyi tanınmalı, sonradan eklenen kısımlar belirlenerek, tarihlendirilmelidir. Bütün bu çalışmalar kaynaklara dayand1rılarak yapılmalı, binalar mümkün olduğunca korunmalıdır. Dünyada ve ülkemizde, korunarak yeniden işlevlendirilen binalarda çelik sistemler kullanılmaktadır. Tarihi yapıların restorasyonunda binaları güçlendirmek ve taşıyıcısında problem olmayan yapılarda tarihi duvarlara zarar vermemek adına çelik sistemlerle taşınan asma katlar yaratılarak çözümler sunulabilir. Kasımpaşa Tuz Ambarı binası bu yöntemle restorasyon çalışması yapılmış ülkemizden bir örnektir. Bu örnekler gibi gün geçtikçe çelik strüktürlerin kullanıldığı, özellikle iç mekân çözümlerinin yapıldığı restorasyon çalışmalarının artacağı düşünülmektedir.

\section{Kaynaklar}

[1] Seyidoğlu, H. (1992). Ekonomik Terimler Ansiklopedik Sözlük. Ankara: Güzem Yayınlar1.

[2] Kariptaş, F. S. (2010). Endüstri Mirası Kapsamındaki Yapıların Yeniden İşlevlendirilmesinde Çelik Strüktür Kullanımı. 5.Ulusal Yapı Malzemesi Kongresi (s. 320-328). İstanbul: TMMOB.

[3] Köksal, G. (2006). İstanbul'daki Endüstri Mirası İçin Koruma ve Yeniden Kullanım Önerileri. ITÜ̈ Dergisi, 125-136.

[4] Köksal, G. (2009). Endüstri Devrimiyle Strüktürel Yapı Elemanı Olan Metal Malzeme ve Koruma Sorunları. Mimarlıkta Malzeme, 45-52.

[5] Kariptaş, F. (2010). Endüstri Mirası Kapsamindaki Yapıların Günümüz Şartlarında Değerlendirilmesi ve Kasımpaşa Tuz Ambarı Örneği. İstanbul.

[6] Terim, B. (2006). Hafif Çelik Çerçeve Sistem. Ege Mimarlık , 44-45.

[7] Sımsıkı, E. (2004). Dış Duvar Bileşenlerinin Birbiri ile ve Çelik Taşıyıcı Sistemle Bütünleştirilmesinde Yapım Teknikleri. Çatıder Sempozyumu. Çatıder.

[8] www.ecarch.com (12.12.2019)

[9] www.fikriyat.com (10.01.2020) 